\title{
Long-distance dispersal by a male sub-adult tiger in a human-dominated landscape
}

\author{
Zehidul Hussain ${ }^{1}$, Pallavi Ghaskadbi ${ }^{1}$, Pramod Panchbhai ${ }^{2}$, Ravikiran Govekar ${ }^{2}$, Parag \\ Nigam $^{1}$, and Bilal Habib ${ }^{1}$ \\ ${ }^{1}$ Wildlife Institute of India \\ ${ }^{2}$ Maharashtra Forest Department
}

January 26, 2022

\begin{abstract}
Conservation of wide-ranging species is a challenge owing to their movement in an increasingly fragmented world. Long-distance dispersal has significant implications for ecosystem functioning, and such movement becomes challenging while navigating through a heterogeneous and human-dominated landscape. Here, we describe one of the longest dispersal journey by a subadult male tiger through GPS telemetry in Central India. We analyzed movement metrics, directionality, and space use during three behavioural stages of dispersal. We also used the clustering method to identify resting and kill sites ( $\mathrm{n}=89$ ). T1-C1 dispersed a straight-line distance of $315 \mathrm{~km}$ over 225 days, moving an average $8.4 \mathrm{~km} /$ day and covering a cumulative displacement of $3000 \mathrm{~km}$. Movement during post-dispersal was higher $($ mean $=465.6 \mathrm{~m} / \mathrm{h})$ than those during dispersal $(\mathrm{mean}=376.6 \mathrm{~m} / \mathrm{h})$ and pre-dispersal (mean $=132.2 \mathrm{~m} / \mathrm{h}$ ), respectively. Moreover, movement during the night was significantly faster than during the day in all three phases. Likewise, during dispersal, the movement was faster (mean $=518.2 \mathrm{~m} / \mathrm{h}$ ) and more directional (knight $=0.19)$ at night than day. The average size of clusters was 1.68 ha and primarily away from human habitation (mean $=1875.6 \mathrm{~m})$. The mean cluster duration $(46.31 \mathrm{hr})$ was higher in the non-forested area but was smaller in size than inside the forest $(\mathrm{p}<0.05)$. The individual crossed roads faster $($ mean $=1880.9 \mathrm{~m} / \mathrm{hr})$ than it travelled during other times. During the post-dispersal phase, T1-C1 established its home range with an area of $319.48 \mathrm{sq} . \mathrm{km}$. (95\% dBBMM). The dispersal event highlights the long-distance and multiscale movement behaviour in a heterogeneous landscape. Moreover, small forest patches play a key role in maintaining large carnivore connectivity while dispersing through a human-dominated landscape. Our study underlines how documenting the long-distance movement and integrating it with modern technology can improve conservation management decisions.
\end{abstract}

\section{Hosted file}

Manuscript . docx available at https : //authorea.com/users/346269/articles/554195-1ong-distancedispersal-by-a-male-sub-adult-tiger-in-a-human-dominated-landscape 

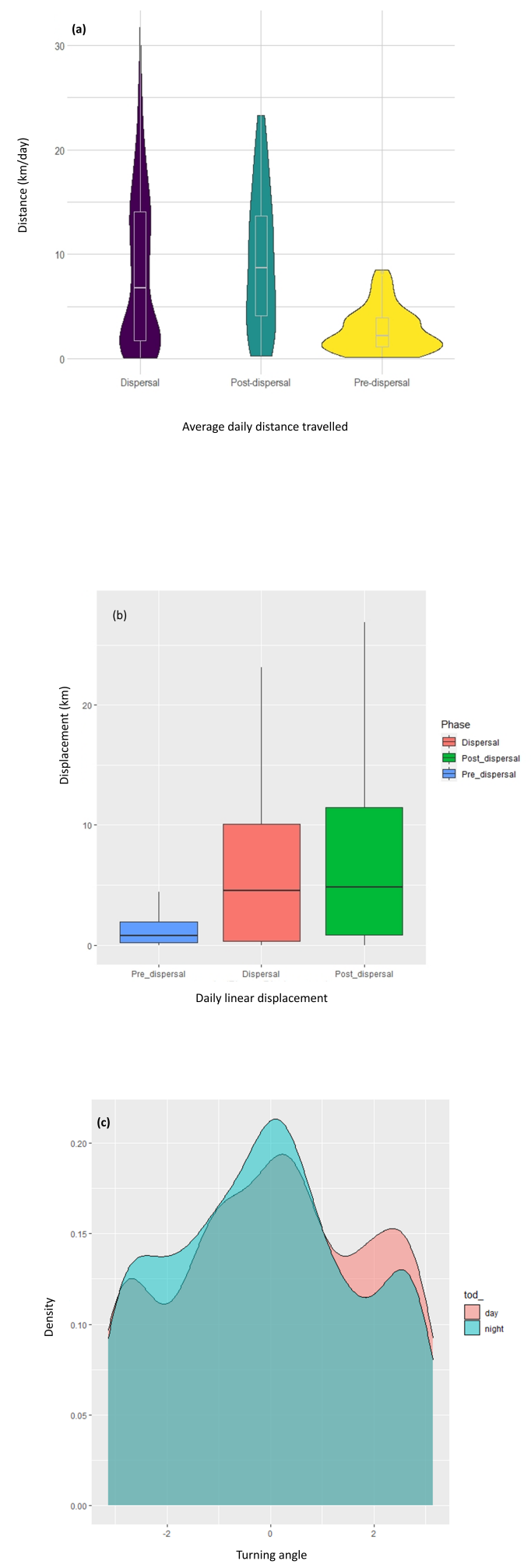

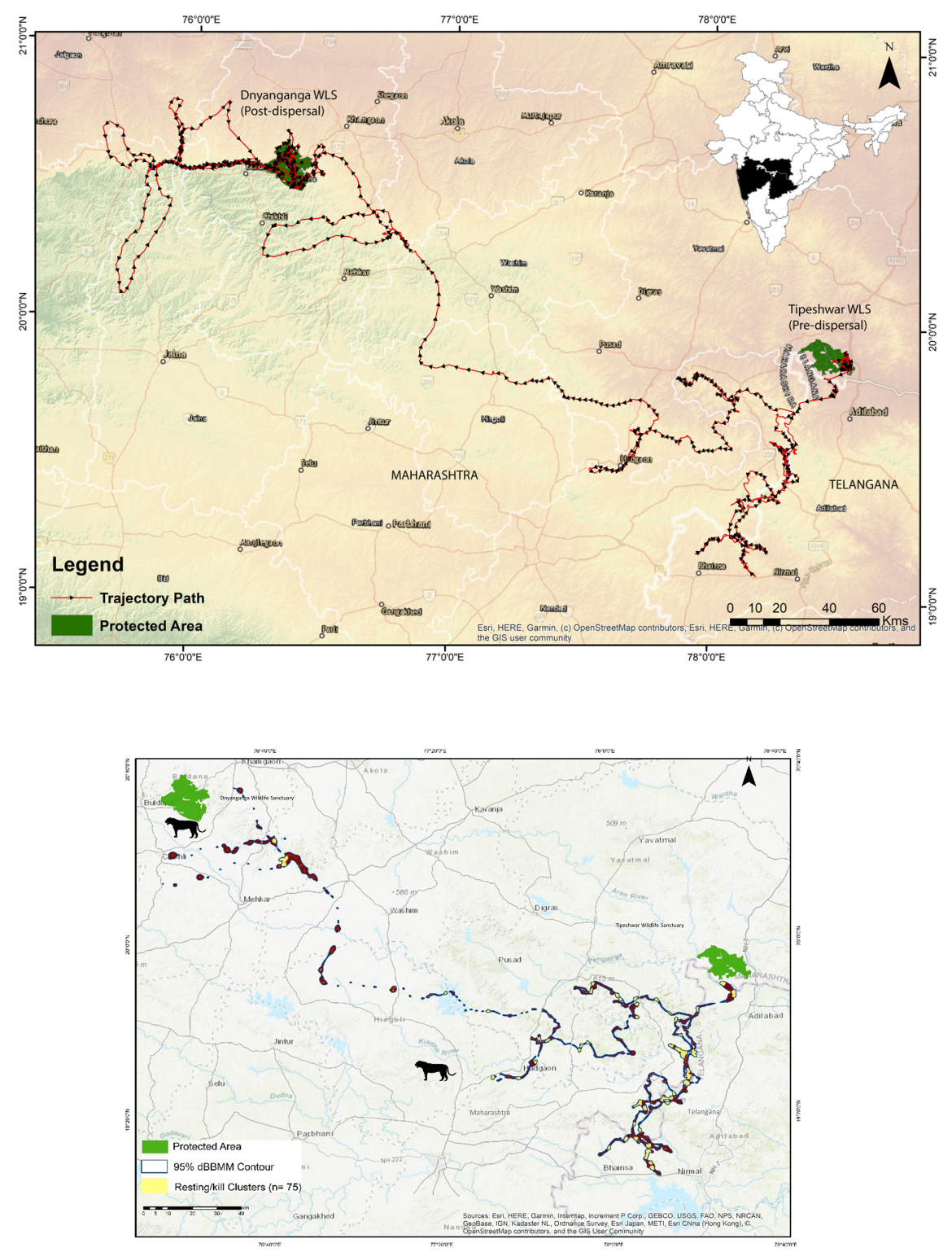